\title{
Itch: Role of Prostaglandins
}

\author{
MALCOLM W. GREAVES, WENDY MCDONALD-GIBSON
}

British Medical fournal, 1973, 3, 608-609

\begin{abstract}
Summary
Prostaglandin $E_{1}$ lowers the threshold of human skin to histamine-evoked itching. Though histamine and other mediators may produce itching by a direct action, itching in inflamed skin can also be explained by a pharmacological synergism in which low concentrations of prostaglandins, which do not themselves cause itching, potentiate itching due to histamine and possibly other agents. Alteration of threshold responses of components of inflammation to other mediators may be an important general role of prostaglandins.
\end{abstract}

\section{Introduction}

Itch is the predominant symptom of skin disease but its pharmacological mechanism has up to now been obscure and its treatment empirical. We now present evidence that prostaglandins, known to be present in increased amounts in inflamed skin (Ängaård et al., 1970; Greaves and Søndergaard, 1970 a; Greaves et al., 1971; Arturson et al., 1973), contribute to itching indirectly by lowering the itch threshold of skin.

\section{Patients and Methods}

The 26 patients studied were of both sexes (age range 12-79 years) suffering from localized non-inflammatory skin conditions and were not taking antipuritic or anti-inflammatory drugs at the time of the study. Their informed consent was obtained in every instance.

Prostaglandin $\mathrm{E}_{1}$ was obtained from Upjohn Ltd. and bradykinin from Sandoz Ltd. Histamine acid phosphate concentrations were expressed as histamine base. Phosphate-buffered saline ( $\mathrm{pH} \mathrm{7.6)}$ was used as a dilutent.

Histamine causes pain when injected intradermally, but itching when applied intraepidermally (Keele and Armstrong, 1964). The interaction between histamine itching and prostaglandin $\mathrm{E}_{1}$ was investigated in the following manner. The skin of the flexor surfaces of both forearms was prepared by washing with ether. Three $1 \mathrm{~cm}^{2}$ areas were lightly scarified on each arm with a No. 12 needle. Great care was taken to avoid any bleeding. A $1 \mathrm{~cm}^{2}$ piece of gauze soaked in prostaglandin $\mathrm{E}_{1}$, bradykinin, or phosphate-buffered saline was placed on each scarified area, and left for 30 minutes. Five minutes after removal of the gauze $0.1 \mathrm{ml}$ of histamine $10 \mu \mathrm{g} / \mathrm{ml}$ was placed on the scarified skin and left for two minutes followed, at 2-minute intervals after drying, by increasing concentrations of histamine up to 1,000 $\mu \mathrm{g} / \mathrm{ml}$ or until itching occurred, whichever was first. A control, in which buffered saline was applied, preceded histamine at each site. The itch threshold was the lowest concentration of histamine which produced itching. In all experiments the concentration of prostaglandin $\mathrm{E}_{1}$ used was $1 \mu \mathrm{g} / \mathrm{ml}$, since higher concentrations sometimes caused oedema which modified itching. Prostaglandin $\mathrm{E}_{1}$ did not cause itching by itself either

\footnotetext{
University Department of Dermatology, Royal Victoria Infirmary, Newcastle upon Tyne NE1 4LP

MALCOLM W. GREAVES, M.D., M.R.C.P., Senior Lecturer

WENDY MCDONALD-GIBSON, Research Assistant
}

in this or in higher concentrations. In each patient three paired comparisons of saline-treated and prostaglandin-treated sites were made using symmetrical sites, and the allocation of prostaglandin or saline to the six sites on the two arms was random. The itch threshold for the prostaglandin-treated and salinetreated sites was calculated as the mean of the three determinations.

\section{Results}

The effect of prostaglandin $E_{1}$ on itch threshold was studied in 23 subjects. In the concentration used, prostaglandin $E_{1}$ did not by itself cause itching after application to scarified skin. Prostaglandin $E_{1}$ increased sensitivity to itching evoked by histamine in 20 of the 23 subjects. In one the sensitivity was lowered and in the remaining two it was unchanged. The mean itch threshold on the prostaglandin-treated site was $115 \mu \mathrm{g} / \mathrm{ml} \pm 18 \mathrm{~S}$.E. of mean histamine compared with $264 \mu \mathrm{g} / \mathrm{ml} \pm 41$ S.E. of mean on the saline-treated site (see fig.). This difference is highly significant $(\mathbf{P}<0.0005)$

Slight erythema occurred at the site of application of prostaglandin $E_{1}$ in a minority of patients. The possibility that in these

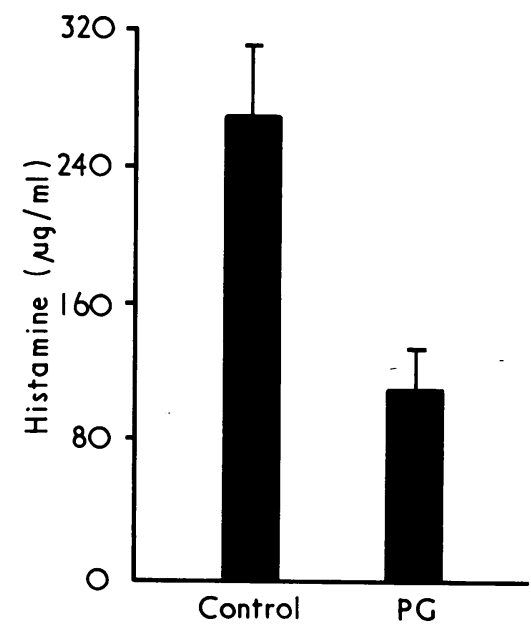

Prostaglandin $E_{1}$ on itch threshold. Each result represents the mean S.E. of mean of 69 observations in 23 subjects and shows lowest concentration histamine causing itching. PG $=$ skin on which prostaglandin $E_{1} \mathrm{\mu g} / \mathrm{ml}$ been applierl. Control = skin on which buffered saline has been applied.

patients the lowering of itch threshold might have been a nonspecific effect of vasodilation was therefore explored. In three patients the skin was scarified in six sites. Buffered saline was applied to three and bradykinin $3 \mu \mathrm{g} / \mathrm{ml}$ to the remaining three sites. This concentration of bradykinin caused erythema about equal in magnitude to the most intense erythema caused by prostaglandin $\mathrm{E}_{1}$. The itch threshold was raised by bradykinin in two patients and unaltered in one. Thus the lowering of itch threshold produced by prostaglandin $\mathrm{E}_{1}$ is unlikely to be a nonspecific response to vasodilation.

\section{Discussion}

The present results clearly show that prostaglandin $\mathrm{E}_{1}$ lowers the threshold of human skin to histamine-evoked itching. We 
therefore suggest that itching in inflamed skin can be the result of pharmacological synergism in which locally synthesized prostaglandins, though not themeslves pruritogenic, sensitize nerve receptors to the pruritic effects of histamine and possibly other mediators. The existence of this pathway would not, of course, exclude the possibility that histamine and other mediators of inflammation may cause itching independently of the presence of prostaglandins as a direct action. The presence of both histamine and prostaglandins has been shown in different types of human cutaneous inflammation (Greaves and Søndergaard $1970 \mathrm{a}, 1970 \mathrm{~b}$ ), and prostaglandins are also potent liberators of endogenous histamine (Von Euler and Eliasson, 1967; Søndergaard and Greaves, 1971). Though low concentrations of prostaglandins $E_{1}$ and $E_{2}$ do not cause itching in skin they do produce signs of inflammation (Solomon et al., 1968; Søndergaard and Greaves, 1971). Our results therefore explain why corticosteroids which inhibit prostaglandin biosynthesis by human skin homogenates (Greaves and McDonald-Gibson, 1972) are antipruritics when applied locally to inflamed skin. Itch and pain are closely related sensations and it is of interest that prostaglandins are known to cause hyperalgesia in skin (Solomon et al., 1968; Ferreira, 1972). Ferriera (1972) also noted that simultaneous infusion of prostaglandin $\mathrm{E}_{1}$ and histamine caused itching. Our results shed new light on the physiology of itch, and they should be extended to include investigation of the effect of prostaglandins on threshold responses of other components of inflam- mation (vascular permeability, leucotaxis) to histamine and other vasoactive agents. We suggest that regulation of threshold responses may be an important general role of prostaglandins in inflammation.

We thank Miss Carol Ellerby for excellent technical help. Prostaglandin $\mathrm{E}_{1}$ was a gift of Upjohn Ltd. (Dr. J. Pyke). This work was financed by the Medical Research Council and Fisons Ltd. (Pharmaceutical Division).

\section{References}

Ängaård, E., Arturson, G., and Jonsson, C.-E. (1970). Acta Physiologica Scandinavica, 80, 46A.

Arturson, G., Hamberg, M., and Jonsson, C.-E. (1973). Acta Physiologica Scandinavica, 87, 270.

Ferriera, S. H. (1972). Nature New Biology, 240, 200.

Greaves, M. W., and Søndergaard, J. (1970 a). Fournal of Investigative Dermatology, 54, 365.

Greaves, M. W., and Søndergaard, J. (1970 b). Archives of Dermatology, $101,418$.

Greaves, M. W., Søndergaard, J., and McDonald-Gibson, Wendy (1971). British Medical fournal, $2,258$.

Keele, C. A., and Armstrong, D. (1964). Substances Producing Pain and Itch, p. 125. London, Edward Arnold.

Solomon, L. M., Juhlin, L., and Kirschenbaum, M. B. (1968). Fournal of Investigative Dermatology, 51, 280.

Søndergaard, J., and Greaves, M. W. (1971). British fournal of Dermatology, 84, 424 . Von Euler, W. S., and Eliasson, R. (1967). Prostaglandins, p. 139. London,
Academic Press.

\section{New Jejunostomy Feed}

\section{J. T. HINDMARSH, R. G. CLARK}

British Medical fournal, 1973, 3, 609-612

\section{Summary}

Three patients with duodenal fistulae were fed solely with an easily prepared, inexpensive jejunostomy feed for 14, 21 , and 23 days respectively. Sodium, potassium, and nitrogen balances became positive, diarrhoea did not develop, and body weight increased. The feed was lifesaving: the patients' superficial veins were thrombosed, and percaval feeding was considered undesirable.

\section{Introduction}

The intravenous and intragastric routes are the usual alternatives for feeding patients with prolonged intestinal dysfunction or alimentary fistulae who cannot be fed by mouth. However, the former requires continuous supervision and engenders a risk of thrombophlebitis-and caval catheterization to avoid that risk introduces others (Wilmore and Dudrick, 1969; Jones and McIntosh, 1973) - and the intragastric route is not suitable for patients with external fistulae of the duodenum. For these latter patients the intrajejunal route is suitable, but, probably because of the usually associated diarrhoea, has been rather neglected.

\footnotetext{
Department of Chemical Pathology, The Royal Infirmary, and Department of Surgery, Northern General Hospital, Sheffield

J. T. HINDMARSH, M.D., M.R.C.PATH., Assistant Professor of Pathology, Dalhousie University, Associate Pathologist (Clinical Chemistry), Nova Scotia Pathology Institute (Present address: Pathology Institute, 5788 University Avenue, Halifax, Nova Scotia, Canada)

R. G. CLARK, M.B., F.R.C.S., Professor of Surgery, Sheffield University
}

The ideal jejunostomy feed should provide an adequate intake of energy, nitrogen, electrolytes, water, vitamins, and essential amino-acids, in a moderate volume of fluid, and should contain the correct proportion of calories derived from carbohydrate, fat, and protein. It should be absorbable without gastric digestion and should not cause diarrhoea. Few previously described formulae fulfil these criteria, and some are also expensive and not easily prepared from materials readily available in a ward kitchen. Therefore, we tried to devise a satisfactory formula with none of these drawbacks.

\section{Methods}

The feed consists mostly of milk, with glucose and arachis oil (Prosparol) to provide additional carbohydrate and fat (table I). Each aliquot is homogenized for five minutes in a blender immediately before administration.

The feed was infused intraduodenally through a gastrostomy catheter (Kay, 1964) or a cholecystectomy T-tube at about

TABLE I- fejunostomy Feed. Daily Aliquot $(2,550 \mathrm{ml})$

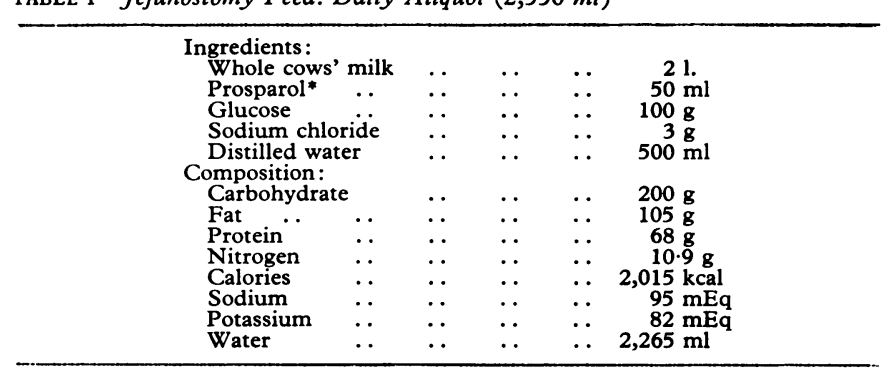

\footnotetext{
*A $50 \%$ emulsion of ground-nut oil in water (B.D.H. Pharmaceuticals Ltd.).
} 